\title{
A low frequency of pancreatic islet insulin-expressing cells derived from cord blood stem cell allografts in humans
}

\author{
C. J. Huang • A. E. Butler • A. Moran • P. N. Rao • \\ J. E. Wagner • B. R. Blazar • R. A. Rizza • \\ J. C. Manivel • P. C. Butler
}

Received: 17 November 2010 / Accepted: 10 January 2011 / Published online: 18 February 2011

(C) The Author(s) 2011. This article is published with open access at Springerlink.com

\begin{abstract}
Aims/hypothesis We sought to establish if stem cells contained in cord blood cell allografts have the capacity to differentiate into insulin-expressing beta cells in humans. Methods We studied pancreases obtained at autopsy from individuals $(n=11)$ who had prior opposite-sex cord blood transplants to reconstitute haematopoiesis. Pancreatic tissue sections were stained first by XY-fluorescence in situ hybridisation and then insulin immunohistochemistry. Pancreases obtained at autopsy from participants without cord blood cell infusions served as controls $(n=11)$.

Results In the men with prior transplant of female cord blood, there were $3.4 \pm 0.3 \% \mathrm{XX}$-positive insulin-expressing
\end{abstract}

C. J. Huang $\cdot$ A. E. Butler $\cdot$ P. C. Butler $(\bowtie)$

Larry L. Hillblom Islet Research Center,

David Geffen School of Medicine,

University of California Los Angeles,

900A Weyburn Place,

Los Angeles, CA 90095, USA

e-mail: pbutler@mednet.ucla.edu

P. N. Rao

Department of Pathology and Laboratory Medicine,

University of California Los Angeles,

Los Angeles, CA, USA

A. Moran · J. E. Wagner • B. R. Blazar

Department of Pediatrics, University of Minnesota,

Minneapolis, MN, USA

R. A. Rizza

Endocrine Research Unit, Mayo Clinic and Medical College,

Rochester, MN, USA

J. C. Manivel

Department of Laboratory Medicine and Pathology,

University of Minnesota,

Minneapolis, MN, USA islet cells compared with $0.32 \pm 0.05 \%(p<0.01)$ in male controls. In women with prior transplant of male cord blood cells we detected $1.03 \pm 0.20 \% \mathrm{XY}$ insulin-expressing islet cells compared with $0.03 \pm 0.03$ in female controls $(p<0.001)$. Conclusions/interpretation Cord blood stem cells have the capacity to differentiate into insulin-expressing cells in nondiabetic humans. It remains to be established whether these cells have the properties of beta cells.

Keywords Beta cell $\cdot$ Cord blood cell $\cdot$ Diabetes $\cdot$ Stem cell

\section{Abbreviation}

FISH fluorescence in situ hybridisation

\section{Introduction}

Type 1 diabetes is characterised by a deficit in beta cells, presumed to be secondary to autoimmune-mediated destruction [1]. Hyperglycaemia in type 1 diabetes can be reversed by pancreas transplantation, but this option is limited by an inadequate supply of organs and the need for chronic immunosuppression [2]. An alternative strategy is to replenish beta cells from stem cells, if the stem cells have the capacity to differentiate into functional beta cells.

Use of allogeneic human embryonic stem cells has shown some promise although significant obstacles remain, such as the need for immunosuppression, the risk of teratoma formation and the need to demonstrate relevant function of cells that develop [3-5].

Another strategy that has been considered is the use of bone marrow derived stem cells or their splenic derivatives as a source of pancreatic beta cells. Some investigators have reported formation of pancreatic beta cells in mice from 
these sources $[6,7]$, but others were unable to reproduce those findings [8-12]. An alternative explanation for reversal of diabetes in mice after treatment with bone marrow derived stem cells is an action of the stem cells to foster regeneration of islet cells, potentially through inducing immune protection [13, 14].

Umbilical cord blood stem cells are another source of stem cells that have been examined for their potential to generate pancreatic beta cells [15-17]. Human umbilical cord blood stem cells have been reported to differentiate into functional pancreatic beta cells in non-obese diabetic immune-deficient mice, but as yet the issue has not been addressed in the human pancreas [18].

In the present study we sought to establish if umbilical cord stem cells transplanted in humans have the capacity to differentiate into insulin-expressing cells. To accomplish this we examined human pancreases obtained at autopsy from 11 recipients of umbilical cord stem cell transplants from opposite-sex donors and 11 age- and sexmatched controls. Survival of the umbilical cord blood transplant recipients ranged from 11 to 377 days following transplantation.

\section{Methods}

Study design/patients To address the question of whether insulin-expressing cells can be derived from cord blood stem cells in human recipients, we sought well-preserved pancreases obtained at autopsy from recipients of cord blood cell allografts from opposite-sex donors to provide a means of tracing the origins of insulin-positive cells. We identified such pancreases from 18 individuals who had been transplanted with an opposite-sex umbilical cord blood graft for haematopoietic rescue after high-dose chemoradiotherapy for the treatment of a marrow failure syndrome or lympho-haematopoietic malignancy. The autopsy study of cord blood recipient pancreas presented here was approved by the University of Minnesota (Institutional Review Board [IRB] 0609E93028). Of the 18 potential cases, seven were excluded from the study owing to inadequate pancreas preservation or sample size. Eleven individuals (five female, six male) were therefore included. As controls we obtained well-preserved pancreases obtained at autopsy from 11 age- and sex-matched individuals who did not have prior cord blood transplants, according to the Mayo Clinic Autopsy Archives. The use of autopsy tissue from age- and sex-matched controls was approved by the Mayo Clinic (IRB 1516-03). Cases were included only if a full autopsy had been performed within $12 \mathrm{~h}$ of death and stored pancreatic tissue was of adequate size and quality. The clinical characteristics of the study subjects and the control subjects are included in Table 1.
Pancreas processing and immunostaining A portion of pancreas tail was obtained at autopsy from each cord blood transplant and control case. After overnight fixation in $10 \%$ formaldehyde, the pancreatic tissue blocks were embedded in paraffin and $4 \mu \mathrm{m}$ sections were obtained from the paraffin blocks. One section from each case was stained with haematoxylin and eosin and examined (by A. E. Butler) to exclude autolysis, with none being excluded on this basis.

At least ten tissue sections from each case were first analysed by fluorescence in situ hybridisation (FISH) to detect $\mathrm{X}$ and $\mathrm{Y}$ chromosome-specific signals and subsequently for insulin staining as previously described [12]. In brief, tissue sections were deparaffinised followed by codenaturation of the target and probe mix at $73^{\circ} \mathrm{C}$ for $3 \mathrm{~min}$ prior to hybridisation with Spectrum Green labelled centromere $\mathrm{X} /$ Spectrum Orange labelled centromere dual colour probes (Abbott-Vysis, Downers Grove, IL, USA). The slides were hybridised overnight with the probes at $42^{\circ} \mathrm{C}$. After a formamide wash procedure, the slides were rinsed and stored with PBS for immunostaining. The slides were fixed in $4 \%$ paraformaldehyde for 30 min and blocked with TBS-T ( $20 \mathrm{mmol} / \mathrm{l}$ Tris-HCL pH7.4 buffer, $500 \mathrm{mmol} / 1$ saline, $0.05 \%$ Tween-20) with $3 \%$ IgG free BSA for $1 \mathrm{~h}$ at room temperature. The slides were then incubated with anti-insulin primary antibody (Dako, Carpinteria, CA, USA; anti-insulin dilution 1:400) overnight at $4{ }^{\circ} \mathrm{C}$ with low-speed rotation. A second anti-guinea pig conjugated with FITC or CY5 was used for fluorescent detection of insulin.

To identify macrophages, tissue sections of all transplant cases and controls were stained first with anti-CD68 (Dako; dilution 1:200) and subsequently with insulin, as described above, prior to the FISH procedure. Using this technique, we could determine if any cells demonstrated colocalisation of CD68 and insulin, indicating phagocytosis of a beta cell by a macrophage.

Morphological evaluation and image analysis In the initial screening for opposite-sex beta cells, all slides were evaluated independently by two investigators (C. J. Huang and A. E. Butler) at high-power magnification $(\times 40$ or $\times 63$ oil lens) using a Leica DM6000 microscope (Leica, Deerfield, IL, USA) connected to a Macintosh computer loaded with Openlab software (Improvision, Lexington, MA, USA). Images were taken at $\times 40$ magnification and stored. Three tissue sections per case were used for XY-FISH and insulin immunohistochemistry. A total number of 3,581 insulinpositive cells were examined from the male cadavers and 2,695 from the female cadavers. Identification of an insulinexpressing cell as being of opposite-sex origin required both cytoplasmic insulin staining and the presence of the XX or $\mathrm{XY}$ chromosome complement (both sex chromosomes being present) as determined by two independent investigators (C. J. Huang and A. E. Butler). Any cells where only a single Y or a 


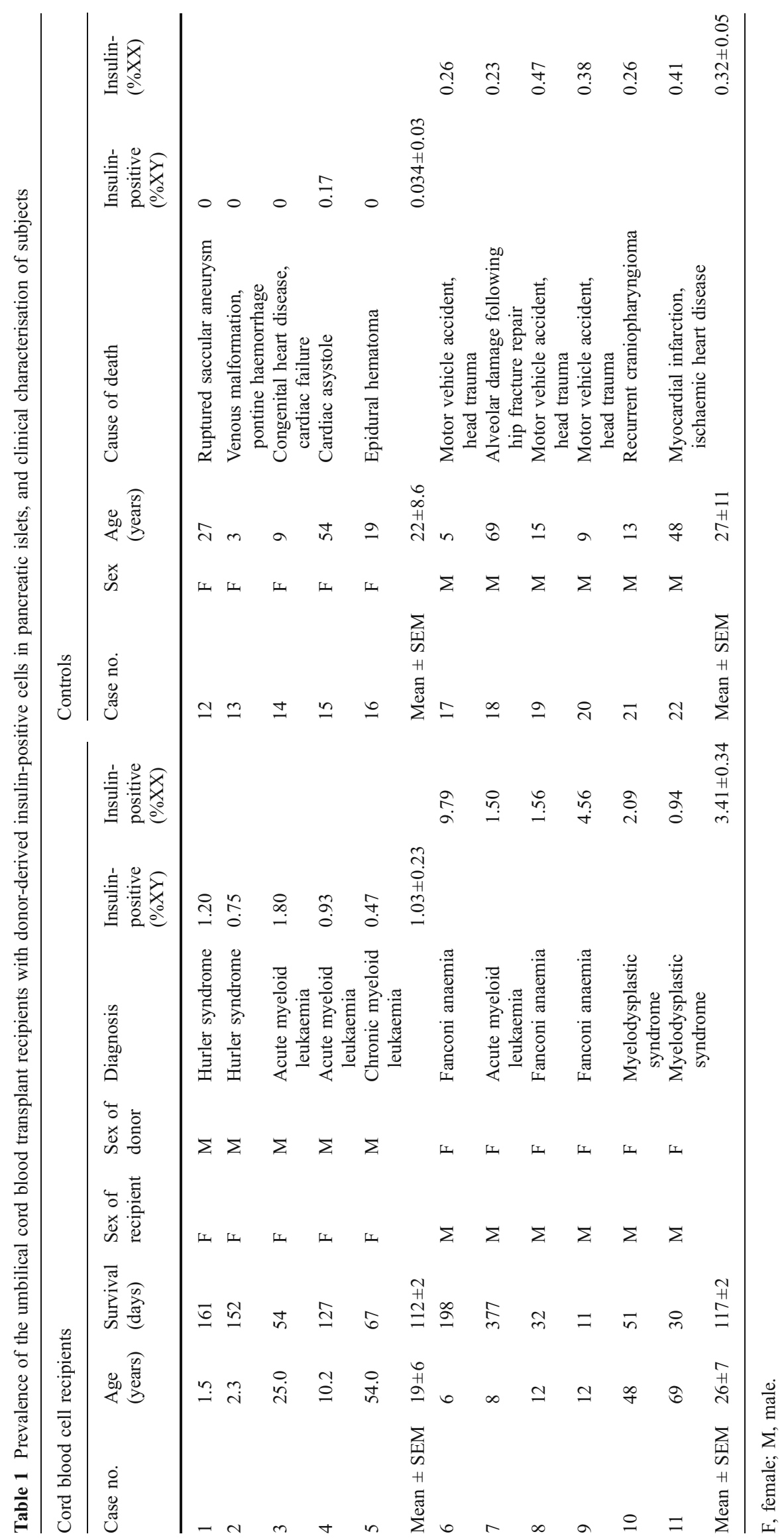


single $\mathrm{X}$ could be visualised in the nucleus were excluded, and cells with an aneuploid complement of sex chromosomes were counted separately as fusion events (see below).

To establish the proportion of cells with an oppositesex complement in the exocrine pancreas, a similar analysis was undertaken in all of the 11 cord blood transplant samples and three of the control samples. Images of exocrine pancreas were taken at $\times 40$ magnification and analysed independently by the two investigators. A total of 5,302 exocrine nuclei were analysed in the six male transplant recipients, and a total of 4,394 exocrine nuclei were analysed from the five female transplant recipients. A total of 12,115 exocrine nuclei were evaluated from five control female individuals and a total of 12,763 exocrine nuclei were evaluated from five control male individuals.

Whenever an islet cell with cytoplasmic insulin staining was identified with an opposite-sex complement of sex chromosomes, or with more than two sex chromosomes, the nuclear diameters of these cells were measured as previously described [19]. For comparison, the nuclear diameters of 30 beta cells were measured from control individuals. A previous study reported that beta cells with polyploidy have larger nuclei than diploid beta cells [20]. Whenever the nuclear diameters of fusion or grafted insulin-positive cells were measured, four nearby host insulin-positive cells were also measured for comparison.

Confocal microscopic analysis In order to further affirm that insulin-expressing cells with an opposite-sex complement of sex chromosomes were indeed a consequence of differentiation from cord stem cells, rather than a consequence of nuclear fusion, pancreases from three of the cord blood transplant individuals were analysed in further detail using confocal microscopy. Imaging was performed using a scanning confocal microscope equipped with argon, green and red helium-neon lasers (Leica). Images were acquired by sequential scanning using a $\times 63$ (1.4 numerical aperture) plan-apochromat oil objective and the appropriate filter combination. $\mathrm{Z}$ sections were captured with a $0.25 \mu \mathrm{m}$ step size. The images $(1,920 \times 1,080$ pixels $)$ were saved as tiff files for later analysis. A total of 2,485 insulin-expressing islet cells were analysed by confocal microscopy in these three cases.

Statistical analysis Data in Table 1 were compared using the unpaired Student's $t$ test and presented as means \pm SEM. A value of $p<0.05$ was taken to be statistically significant. ANOVA analysis with Fisher's post hoc test was used where appropriate. Regression analysis was performed using Statistica, Version 6 (StatSoft, Tulsa, OK, USA).

\section{Results}

Sex chromosome designation in beta cells of control cases In pancreatic islets from male controls that had not received a cord blood stem cell transplant we identified $0.32 \pm 0.05 \%$ (range $0.23-0.47 \%$ ) beta cells with an XXchromosomal complement, presumably reflecting the admixture of maternal circulating haematogenous stem cells with fetal circulation at or before birth. The presence of beta cells with opposite-sex sex chromosomes (XY) was less common in female controls, being detected in only one of the five female control individuals, resulting in an overall frequency of $0.03 \pm 0.03 \%$. The one female cadaver in which beta cells with an opposite-sex complement of sex chromosomes were identified (with a frequency of $0.17 \%$ ) was a 54-year-old woman (case no. 15) who had given birth to a male child. Thus, XY-positive beta cells in the female controls are likely to reflect the admixture of residual male infant-derived haematogenous stem cells at or before birth.

Sex chromosome designation in insulin-expressing cells of cord blood transfusion recipients The frequency of insulinexpressing cells with a female complement of sex chromosomes was increased in male individuals who had received a female donor cord blood stem cell transplant compared with male controls $(3.41 \pm 0.34$ vs $0.32 \pm 0.05, p<0.01)$
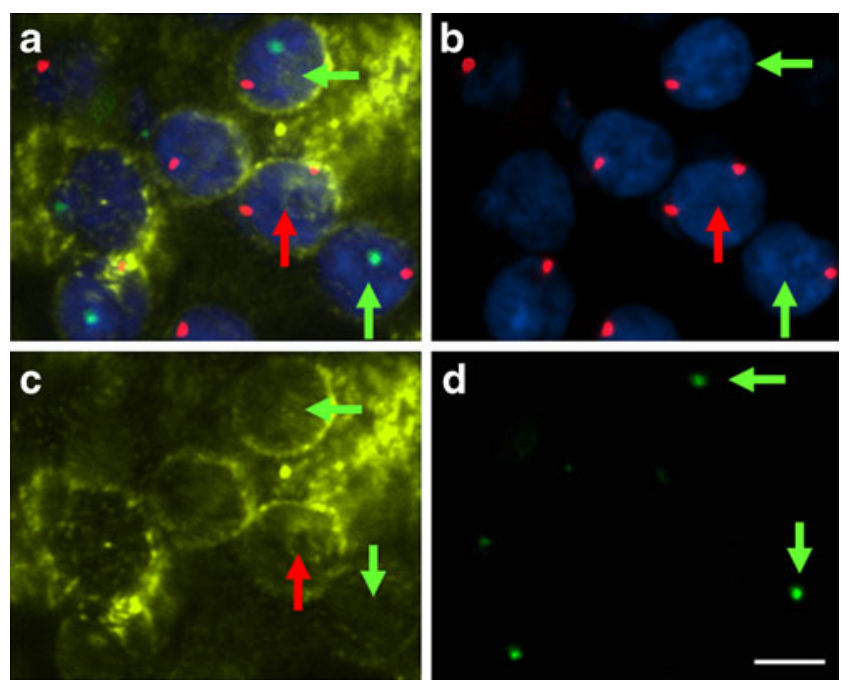

Fig. 1 Islet in male recipient of female umbilical cord blood transplant. A magnified image (scale bar $5 \mu \mathrm{m}$ ) showing the presence of an insulin-expressing cell with XX chromosomes (red arrow) in the nucleus, $\mathrm{X}$ chromosomes (red dots by FISH) and cytoplasmic insulin (yellow by immunofluorescence) from case no. 8. Cells with the (male) XY sex chromosomes are shown by green arrows (Y chromosome by FISH green dot). Only cells with both sex chromosomes present in the nuclear section were attributed a sex designation as described in the methods. (a) Merged four-colour image; (b) X chromosome, red; (c) insulin in CY5 (pseudo-colour); (d) Y chromosome, green; nuclei, DAPI (blue) 

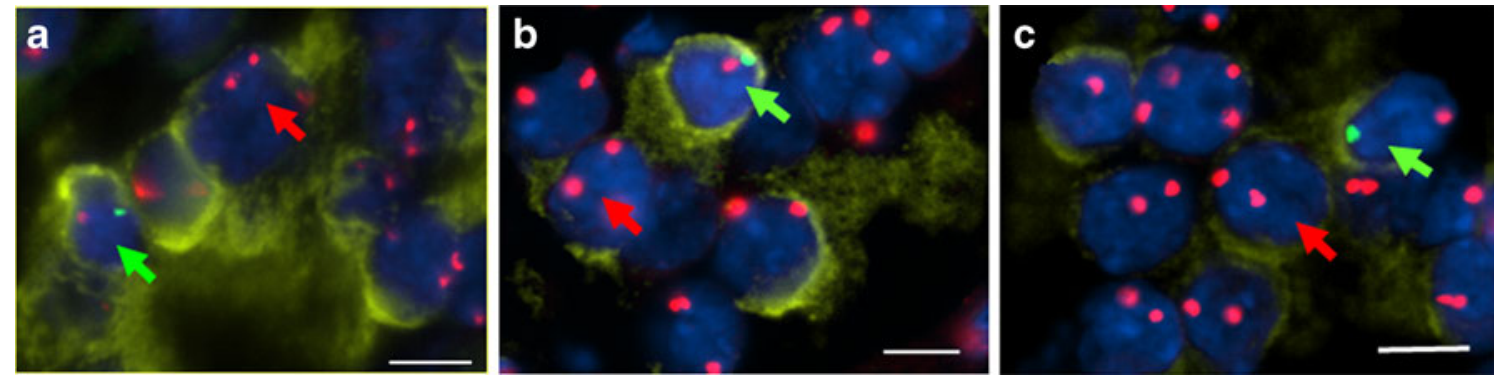

Fig. 2 Islet in female recipient of a male umbilical cord blood transplant. A magnified image (scale bar $5 \mu \mathrm{m}$ ) showing the presence of insulin-expressing cells with male XY sex chromosomes (green arrows) in the nucleus as well as host cells with (female) XX sex chromosomes (red arrows). Cytoplasmic insulin is yellow by immunofluorescence. All images are from case no. 1. Only cells with both sex chromosomes present in the nuclear section were attributed a sex designation as described in the methods. (a-c) Merged four-colour images; X chromosome, red; Y chromosome, green; insulin in CY5 (pseudo-colour); nuclei, DAPI (blue)
(Fig. 1). The case with the highest frequency of oppositesex beta cells was $9.8 \%$ in a 6 -year-old boy with Fanconi anaemia who had survived for 198 days after receiving a female umbilical cord blood cell transplant (case no. 6). As many as ten insulin-expressing cells were present in a single section in some islets in this case. We also observed an increased frequency of insulin-expressing cells with a male complement of sex chromosomes in female individuals who had been transplanted with male cord blood cells when compared with control females $(1.03 \pm 0.23$ vs $0.03 \pm$ $0.03 \%, p<0.001$; Figs 2, 3). As is apparent from Table 1, there was no relationship between the length of life after cord blood stem cell transplant and the percentage of insulin-expressing cells with an opposite-sex complement of sex chromosomes. While there were too few cases available to establish a recipient effect on the percentage of opposite-sex insulin-expressing cells, it is of interest that the two individuals with the highest percentage of opposite-sex insulin-expressing cells both had Fanconi anaemia, a condition characterised by a high risk for diabetes and glucose intolerance during the transplant process [21]. None of the three individuals with Fanconi

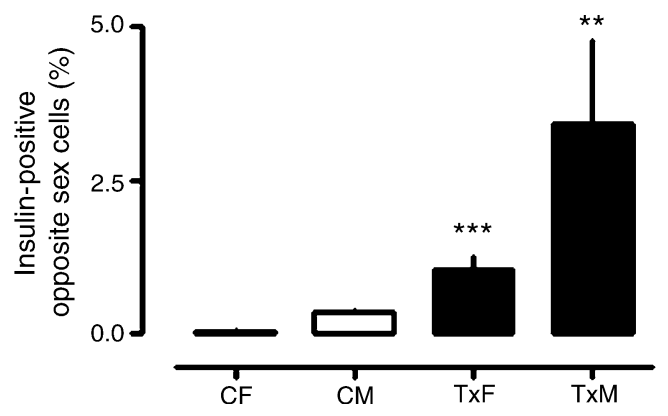

Fig. 3 Mean \pm SEM percentage of insulin-positive cells detected with an opposite-sex complement of sex chromosomes in female controls $(\mathrm{CF})$, male controls $(\mathrm{CM})$, female recipients of male cord blood transplants $(\mathrm{TxF})$ and male recipients of female cord blood cell transplants (TxM). ${ }^{* * *} p<0.001, \mathrm{TxF}$ vs CF; ${ }^{* *} p<0.01 \mathrm{TxM}$ vs CM anaemia evaluated here had diabetes or immune cell infiltration in islets.

All examples of insulin-expressing cells with a complement of chromosomes reflecting the umbilical cord blood cell donor were present in pancreatic islets, rather than in the individual beta cells found scattered in the exocrine pancreas or in exocrine ducts. This might be because the islet environment favours umbilical cord blood multi-progenitor cell recruitment and differentiation, or simply be a statistical issue with an insufficient number of scattered beta cells to reveal a relatively low percentage phenomenon.

While the presence of insulin-expressing cells with sexmismatched chromosomes after umbilical cord blood stem cell transplant could indicate differentiation of cord blood stem cells into pancreatic beta cells, another explanation that has been proposed for such a finding is fusion of donor cells with host cells leading to mosaicism. We next sought to establish if this was the basis for the increase in opposite-sex insulinexpressing cells in cord blood stem cell transplant recipients.

Fusion of host beta cells with cord blood cells Using confocal microscopy to examine the nuclei of insulinexpressing cells with an apparent mismatch of the sex chromosomes (see above) we detected examples of nuclear fusion revealed by two sets of sex chromosomes in the same nucleus (Fig. 4). Of the 2,485 beta cells from the three transplant cases that were analysed by confocal microscopy (Fig. 5), the frequency of opposite-sex insulin-expressing cells was $1.5 \%$. In addition, $0.76 \%$ of insulin-positive cells were determined to have polyploid (aneuploid) nuclei (three or more sex chromosomes). Moreover, where cell fusion had occurred it was readily apparent from the enlarged nucleus that accompanied the two sets of sex chromosomes (Fig. 4b). The mean nuclear diameter of beta cells with two sets of sex chromosomes was $\sim 40 \%$ greater than that of beta cells with a single set of sex chromosomes $(9.5 \pm 0.4$ vs $6.8 \pm 0.3 \mu \mathrm{m}, p<0.001)$, as previously described [20]. 

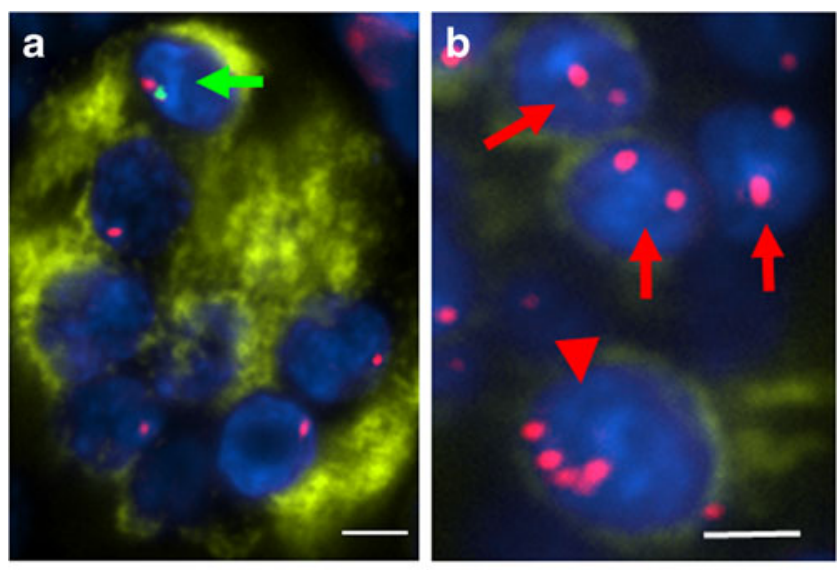

C

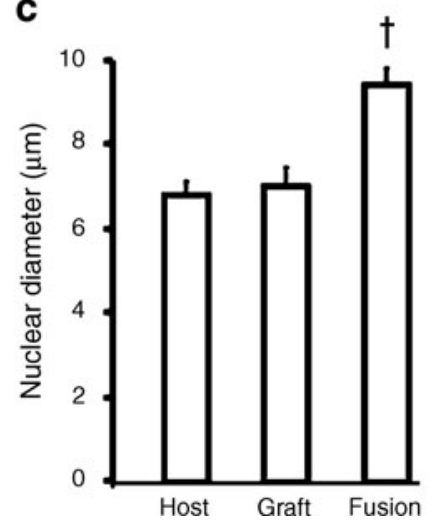

Fig. 4 Nuclear enlargement with aneuploidy. a Nuclear diameter is comparable to adjacent beta cells in an example of an insulinexpressing cell with a male complement of sex chromosomes (green arrow) in a female recipient of a male cord blood transplant (case no. 1) (scale bar $5 \mu \mathrm{m}$ ). b An example of polyploidy (arrowhead) with nuclear enlargement in a female individual (case no. 1). Adjacent diploid beta cells have smaller nuclei (arrows) (scale bar $5 \mu \mathrm{m}$ ). c Mean \pm SEM nuclear diameter of diploid host beta cells (host); insulin-positive cells with sex mismatch sex chromosomes or with polyploidy $\left({ }^{\dagger} p<0.0001\right)$

In contrast, the nuclear diameter of insulin-expressing cells with a single set of opposite-sex sex chromosomes was no different from that of beta cells with the host complement of sex chromosomes ( $7.1 \pm 0.4$ vs $6.8 \pm 0.3 \mu \mathrm{m}$, $p=0.63$; Fig. 4). We conclude that the majority of insulinexpressing cells with a complement of sex chromosomes reflecting that of the cord blood donor rather than the host were not a consequence of nuclear fusion.

Are insulin-positive cells with opposite-sex sex chromosomes macrophages? Another plausible explanation for insulin-positive cells with a sex chromosome complement of the opposite sex is the phagocytosis of a host beta cell by a donor macrophage (derived from the haematogenous lineage), resulting in a cell with cytoplasmic insulin immunoreactivity. We did not detect colocalisation of the macrophage marker CD68 with insulin immunoreactivity in pancreatic tissue sections in either umbilical cord blood stem cell recipients or controls (Fig. 6). Indeed, given the absence of autoimmune type 1 diabetes in any of the evaluated cases, as expected, the frequency of macrophages detected in islets was very low, with one exception in a recipient who had an extensive inflammatory infiltrate in some regions of the pancreas (case no. 7 and Fig. 6). Even in this case, we identified no insulin immunoreactivity coincident with the abundant macrophages. It is therefore unlikely that the insulin-positive cells with a complement of sex chromosomes from an opposite-sex cord blood cell donor represented macrophages after phagocytosis of a beta cell.

Grafted cells in exocrine tissue area Next, we determined the frequency of the opposite-sex cells in the exocrine pancreas of each of the ten transplant recipients (Fig. 7). The frequency of opposite-sex cells in exocrine pancreas was $2.20 \pm 0.37 \%$ (range $1.1-3.1 \%$ ). A total of 9,763 pancreatic exocrine nuclei were evaluated in the ten cord blood transfusion recipients $(5,369$ exocrine nuclei in male recipients and 4,394 exocrine nuclei in female recipients). There was no difference between male and female transfusion recipients in terms of the percentage of opposite-sex cell engraftment in pancreatic exocrine tissue (male recipients had $2.14 \pm 0.44 \%$ opposite-sex cells in exocrine pancreatic tissue, female recipients had $2.26 \pm$ $0.37 \%$ opposite-sex cells in exocrine pancreatic tissue). A similar relationship was found between the frequency of opposite-sex cells in exocrine pancreas and the duration of survival after cord blood infusion to that previously observed in humans following opposite-sex bone marrow transplants [12]. As expected, the frequency of opposite-sex sex chromosomes in the exocrine cells of the control cases was lower than in the cord blood stem cell recipients. In four of the five female controls no opposite-sex complement of sex chromosomes was detected and in one female control (case 15, Table 1) two exocrine cells out of 3,608 evaluated had XY sex chromosomes detected, this being the same individual with a comparably low level of microchimerism in beta cells, presumably due to bearing a male infant. In contrast, a low level of microchimerism was detected in all six of the male controls evaluated, again comparable with that observed in beta cells, mean $0.32 \pm 0.05 \%$.

\section{Discussion}

We sought to establish if umbilical cord blood stem cells include those that have the capacity to differentiate into pancreatic beta cells in humans. Using sex chromosomes as 
Fig. 5 Confocal images of an insulin-expressing cell. Sequential $0.25 \mu \mathrm{m} \mathrm{z}$ axis images of an insulin-expressing cell in the islet of a female recipient of a male cord blood transplant (case no. 1) affirming the presence of just two sex chromosomes (X, red arrow; Y, green arrow) and assuring that the nucleus is surrounded by insulin immunoreactivity (scale bar $5 \mu \mathrm{m})$. X chromosome, red; $\mathrm{Y}$ chromosome, green; insulin in CY5 (pseudo-colour); nuclei, DAPI (blue)
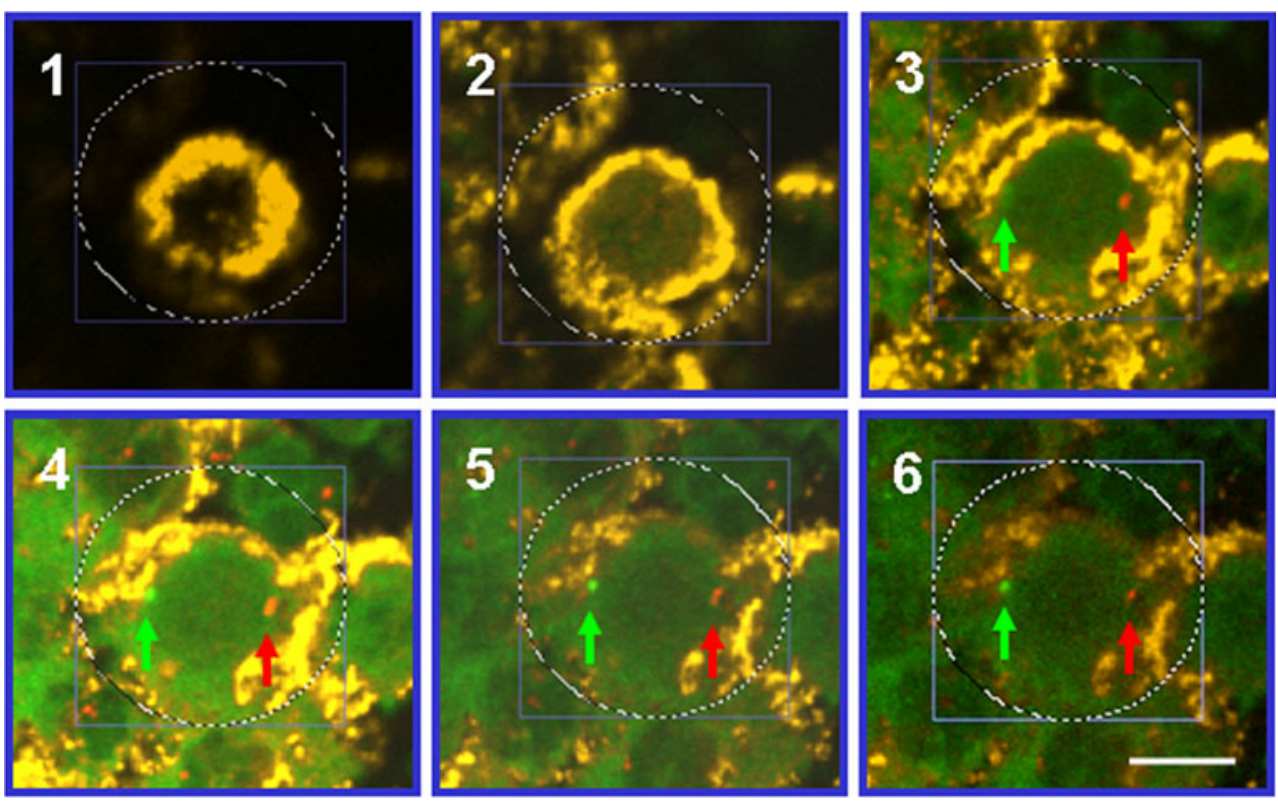

a surrogate for lineage tracing, the present study reveals that allograft cord blood stem cell transplants do include cells with a capacity to differentiate into cells that express insulin and have the appearance of beta cells in islets of recipients. It remains to be established whether these cells secrete insulin in a regulated manner and, if they do, whether they can be formed in sufficient quantity to be therapeutically useful.

We observed marked variability between individuals in the percentage of insulin-expressing islet cells with an opposite-sex (donor) complement of sex chromosomes. There was no pattern of increased proportion of insulinexpressing islet cells derived from donor cells in pancreas examined at autopsy with the time after cord blood
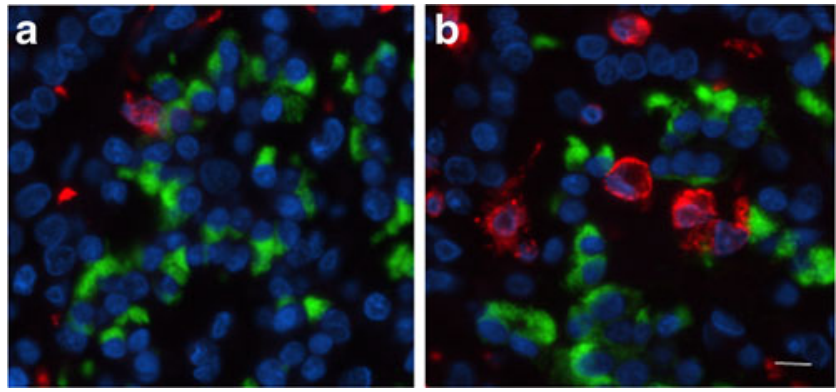

Fig. 6 Macrophages in islets. The macrophage immunomarker CD68 (red) was used with insulin staining (green) and DAPI (blue) to establish to what extent insulin-expressing cells in the cases studied here are macrophages following phagocytosis of insulin. As with prior reports of non-diabetic individuals, macrophages were rarely identified in islet sections of ten of 11 cases of prior umbilical cord blood transplants, and in none was insulin immunoreactivity detected in macrophages. In $\mathbf{a}$ and $\mathbf{b}$, images are from two islets from case no. 7 in which an inflammatory infiltrate was noted in the haematoxylin and eosin-stained sections, confirmed here to be composed of macrophages with no insulin immunoreactivity (scale bar $10 \mu \mathrm{m}$ ) transplant. This may imply that, to the extent that there is a capacity for cord blood stem cells to form insulinexpressing islet cells, this occurs early and there is minimal further contribution from engrafted donor cord blood stem cells. To make a first estimate of the potential for beta cell replacement through umbilical cord blood cell transplant, if umbilical cord blood cell recipients were to accomplish an increment in beta cells of approximately $2 \%$ per treatment, then 25 treatments would be required to establish a beta cell mass of $\sim 50 \%$ of normal, a target that approximates the requirement to establish glucose homeostasis [3, 22, 23]. It is possible that umbilical cord blood stem cells might be more frequently recruited to islets in the setting of inflammation in type 1 diabetes, and perhaps transdifferentiated towards a beta cell phenotype by hyperglycaemia. However, under these circumstances it is also likely that

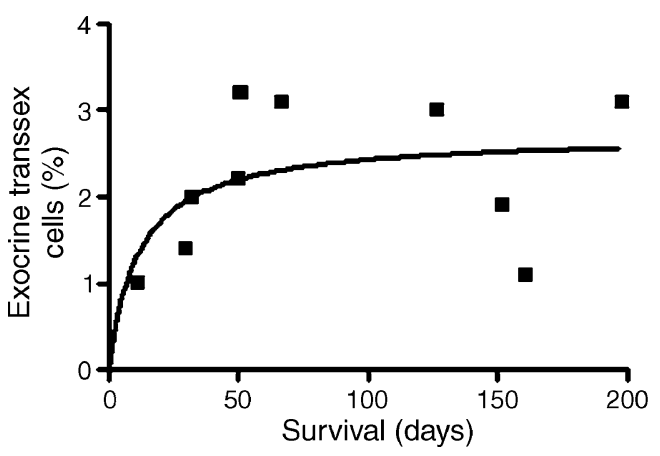

Fig. 7 Relationship between percentage of opposite-sex exocrine cells and survival from cord blood cell transfusion. There was a gradual increase to steady state at between 50 and 100 days after cord blood cell transplants. Data obtained from 8,743 nuclei in ten recipients of cord blood cell transplants 
any beta cells that arise from cord blood stem cells will be subject to accelerated loss through autoimmunity [24]. It is of note there was no discernable increase or preservation of insulin secretion in child recipients of autologous cord blood infusions after recent-onset type 1 diabetes mellitus [25].

It is important to consider the validity of the conclusion that umbilical cord blood stem cells give rise to pancreatic beta cells. A limitation of the present work is that the pathology leading to death in the cord blood stem cell recipients is not the same as that in the control individuals. Moreover the cord blood stem cell recipients were subject to marrow ablation prior to transplant. If maternal microchimerism in pancreatic beta cells was to be selectively enhanced in individuals with haematological malignancies, Hurler syndrome, Fanconi anaemia and/or bone marrow ablation, this could give the impression of insulinexpressing cells derived from cord blood stem cells. On the other hand, in a prior study of individuals with haematological malignancies treated with marrow ablation and subsequent bone marrow transplant from opposite-sex donors, there was no detectable increase in insulinexpressing cells by use of the exact same methods used here [12].

Ideally, to establish the origins of differentiated cells, lineage tracing is used. However, conventional lineage studies are not possible in humans. Prior transplantation of stem cells derived from an opposite-sex donor provides a unique opportunity to subsequently identify differentiated cells that have arisen from the stem cells, using the sex chromosomes as a surrogate for lineage tracing. This approach, however, is not without pitfalls. One potential source of error is maternal microchimerism of beta cells arising from the maternal circulation before, or at the time of, birth. The frequency of maternal microchimerism (XX chromosomes) identified in pancreatic beta cells of nondiabetic male children has previously been reported to be approximately $0.5 \%[26,27]$ and this could have contributed to the higher percentage of insulin-positive cells with an opposite complement of sex chromosomes in male recipients reported here. Another factor that is likely to have contributed to this imbalance is that, using the FISH technique with concurrent insulin staining in the same sections, the $\mathrm{Y}$ chromosome is less readily detected than the $\mathrm{X}$ chromosome. Given the conservative approach that we adopted to permit the conclusion of an insulin-positive cell of an opposite-sex origin (both sex chromosomes must be detected in the same nucleus), it is inevitable that we have some false negatives, and this will be more common in female recipients of male umbilical cord blood transplantation.

Another potential source of error is nuclear fusion leading to polyploidy [28]. We used two approaches to minimise this error. To the extent that was practicable, we employed confocal microscopy to examine the nuclei in multiple planes to exclude more than two sex chromosomes. Second, we compared the nuclear diameter of insulin-positive cells bearing an opposite-sex complement of sex chromosomes to that of beta cells surrounding them. In reality, neither of these approaches is completely foolproof and so some fraction of the insulin-expressing cells assigned to be of donor origin may have been due to unrecognised cell fusion.

An additional potential source of false-positive identification of apparent stem cell differentiation into somatic cells of interest is mismatching of the nucleus with cytoplasm. This error is a particular concern when insulin immunostaining to detect beta cells and the FISH technique to identify sex chromosomes are performed on separate adjacent tissue sections. To overcome that problem we previously developed the approach of performing immunohistochemistry for insulin on the same tissue section after the FISH technique [12]. This approach reduces the risk of false positives but, because some cytoplasm is lost during the nuclear etching procedure required for the FISH procedure, it increases false negatives. In this respect, our method would result in undercounting of opposite-sex cells rather than overcounting, giving a conservative error.

Finally, it has long been appreciated that host beta cells that have undergone phagocytosis by a donor macrophage may be mistakenly identified as beta cells arising from stem cells, because of the insulin identified in the macrophage cytoplasm. This is more likely to be a technical challenge under conditions of islet inflammation, such as in type 1 diabetes. In the present study, as in prior reports of nondiabetic humans, we rarely identified macrophages in an islet cross section, the frequency being much lower than that of the detected insulin-expressing cells with an opposite-sex complement of sex chromosomes. Moreover we did not find coincident CD68 and insulin immunoreactivity in the same cell in any sample.

In conclusion, we report that umbilical cord blood cells do have the capacity to migrate to the pancreatic islet and differentiate into insulin-expressing cells in humans. This is in contrast to the absence of insulin-expressing cells with an opposite-sex complement of sex chromosomes present in human pancreas after prior bone marrow transplant, when the same methods were used as here [11]. By implication, it appears that the stem cells in cord blood may hold more promise for formation of pancreatic beta cells than those in bone marrow. However, it remains to be determined whether insulin-expressing cells that arise from cord blood cells in humans have the physiological properties of beta cells. Also, it remains to be determined whether functional beta cells can thus be generated in sufficient number, and protected from autoimmunity, to provide useful insulin secretion in patients with type 1 diabetes. 
Acknowledgements Studies were supported by grants from the National Institute of Health (DK059579) and the Larry Hillblom Foundation. We thank E. Manesso for her statistical advice, J. Jang for help in image acquisition and K. Linzmeier for her help in measuring the nuclear diameter. We are grateful to H. Cox and R. Galasso from the Larry Hillblom Islet Research Center and M. Torres and S. Cucueco from the Cytogenetics Laboratory for their excellent technical support and acknowledge the support and excellent suggestions of our colleagues at the Larry Hillblom Islet Research Center, A. Bhushan, T. Gurlo and S. Georgia.

Duality of interest The authors declare that there is no duality of interest associated with this manuscript.

Open Access This article is distributed under the terms of the Creative Commons Attribution Noncommercial License which permits any noncommercial use, distribution, and reproduction in any medium, provided the original author(s) and source are credited.

\section{References}

1. Eisenbarth GS (2010) Banting lecture 2009: an unfinished journey: molecular pathogenesis to prevention of type $1 \mathrm{~A}$ diabetes. Diabetes 59:759-774

2. Robertson RP, Davis C, Larsen J, Stratta R, Sutherland DE (2006) Pancreas and islet transplantation in type 1 diabetes. Diabetes Care 29:935

3. Kroon E, Martinson LA, Kadoya K et al (2008) Pancreatic endoderm derived from human embryonic stem cells generates glucose-responsive insulin-secreting cells in vivo. Nat Biotechnol 26:443-452

4. Matveyenko AV, Georgia S, Bhushan A, Butler PC (2010) Inconsistent formation and nonfunction of insulin-positive cells from pancreatic endoderm derived from human embryonic stem cells in athymic nude rats. Am J Physiol Endocrinol Metab 299:E713-E720

5. Mfopou JK, Chen B, Sui L, Sermon K, Bouwens L (2010) Recent advances and prospects in the differentiation of pancreatic cells from human embryonic stem cells. Diabetes 59:2094-2101

6. Kodama S, Kuhtreiber W, Fujimura S, Dale EA, Faustman DL (2003) Islet regeneration during the reversal of autoimmune diabetes in NOD mice. Science 302:1223-1227

7. Ianus A, Holz GG, Theise ND, Hussain MA (2003) In vivo derivation of glucose-competent pancreatic endocrine cells from bone marrow without evidence of cell fusion. J Clin Invest 111:843-850

8. Chamson-Reig A, Arany EJ, Hill DJ (2010) Lineage tracing and resulting phenotype of haemopoietic-derived cells in the pancreas during beta cell regeneration. Diabetologia 53:2188-2197

9. Chong AS, Shen J, Tao J et al (2006) Reversal of diabetes in nonobese diabetic mice without spleen cell-derived beta cell regeneration. Science 311:1774-1775

10. Nishio J, Gaglia JL, Turvey SE, Campbell C, Benoist C, Mathis D (2006) Islet recovery and reversal of murine type 1 diabetes in the absence of any infused spleen cell contribution. Science 311:1775-1778
11. Suri A, Calderon B, Esparza TJ, Frederick K, Bittner P, Unanue ER (2006) Immunological reversal of autoimmune diabetes without hematopoietic replacement of beta cells. Science 311:1778-1780

12. Butler AE, Huang A, Rao PN et al (2007) Hematopoietic stem cells derived from adult donors are not a source of pancreatic betacells in adult nondiabetic humans. Diabetes 56:1810-1816

13. Hess D, Li L, Martin M et al (2003) Bone marrow-derived stem cells initiate pancreatic regeneration. Nat Biotechnol 21:763-770

14. Jayaraman S, Patel T, Patel V et al (2010) Transfusion of nonobese diabetic mice with allogeneic newborn blood ameliorates autoimmune diabetes and modifies the expression of selected immune response genes. J Immunol 184:3008-3015

15. Korbling M, Robinson S, Estrov Z, Champlin R, Shpall E (2005) Umbilical cord blood-derived cells for tissue repair. Cytotherapy 7:258-261

16. Ishikawa F, Yasukawa M, Yoshida S et al (2004) Human cord blood- and bone marrow-derived CD34+ cells regenerate gastrointestinal epithelial cells. Faseb J 18:1958-1960

17. Minamiguchi H, Ishikawa F, Fleming PA et al (2008) Transplanted human cord blood cells generate amylase-producing pancreatic acinar cells in engrafted mice. Pancreas 36:e30-e35

18. Zhao Y, Wang H, Mazzone T (2006) Identification of stem cells from human umbilical cord blood with embryonic and hematopoietic characteristics. Exp Cell Res 312:2454-2464

19. Meier JJ, Butler AE, Saisho Y et al (2008) Beta-cell replication is the primary mechanism subserving the postnatal expansion of beta-cell mass in humans. Diabetes 57:1584-1594

20. Ehrie MG, Swartz FJ (1974) Diploid, tetraploid and octaploid beta cells in the islets of Langerhans of the normal human pancreas. Diabetes 23:583-588

21. Polgreen LE, Thomas W, MacMillan ML, Wagner JE, Moran A, Petryk A (2009) First phase insulin release and glucose tolerance in children with Fanconi anaemia after hematopoietic cell transplantation. Pediatr Blood Cancer 53:191-196

22. Matveyenko AV, Butler PC (2008) Relationship between betacell mass and diabetes onset. Diabetes Obes Metab 10(Suppl 4):23-31

23. Saisho Y, Butler AE, Manesso E et al (2010) Relationship between fractional pancreatic beta cell area and fasting plasma glucose concentration in monkeys. Diabetologia 53:111-114

24. Velthuis JH, Unger WW, van der Slik AR et al (2009) Accumulation of autoreactive effector $\mathrm{T}$ cells and allo-specific regulatory $\mathrm{T}$ cells in the pancreas allograft of a type 1 diabetic recipient. Diabetologia 52:494-503

25. Haller MJ, Wasserfall CH, McGrail KM et al (2009) Autologous umbilical cord blood transfusion in very young children with type 1 diabetes. Diabetes Care 32:2041-2046

26. Rust DW, Bianchi DW (2009) Microchimerism in endocrine pathology. Endocr Pathol 20:11-16

27. Nelson JL, Gillespie KM, Lambert NC et al (2007) Maternal microchimerism in peripheral blood in type 1 diabetes and pancreatic islet beta cell microchimerism. Proc Natl Acad Sci USA 104:1637-1642

28. Vassilopoulos G, Wang PR, Russell DW (2003) Transplanted bone marrow regenerates liver by cell fusion. Nature 422:901-904 